\title{
A brief look at the perception of pain management in sickle cell crisis
}

\section{Introduction}

Sickle cell syndromes can be divided into sickle cell trait (SCT) and sickle cell disease (SCD). These syndromes are best characterized as a group of hereditary conditions with the presence of sickle cell hemoglobin in red blood cells. ${ }^{1}$ The sickle cell trait is characterized by normal hemoglobin levels and is significant because of its heterozygous carrier state. About 1 in 13 Black or African-American babies is born with sickle cell trait (SCT). ${ }^{2}$ Sickle cell disease is described as a chronic hematological disorder that is acquired through genetics, but can be of homozygous or compounded heterozygous inheritance. Sickle cell disease affects millions of people worldwide and is most common in people with African heritage. It is estimated to affect 100,000 Americans and millions of other people throughout the world, particularly those whose ancestors came from sub-Saharan Africa and Spanish speaking regions of the Western Hemisphere. ${ }^{1,2}$

Sickle cell disease is further characterized by the production of hemoglobin $\mathrm{S}$ in the erythrocyte, vaso-occlusion, and hemolytic anemia. Hemoglobin S differs from normal hemoglobin A by a single amino acid substitution of valine for glutamic acid. Sickle cell disease involves multiple organ systems and acute complications. Sickle cell anemia is associated with pain episodes, micro vascular disruption of organs (spleen, liver, bone marrow, kidney, brain, and lungs), gallstones, priapism, leg ulcers and anemia. Other complications includes: ocular disease, pregnancy related problems, and anemia. Sick cell Beta-thalassemia is milder severity than sickle cell anemia because production of some hemoglobin A. Common acute complications associated with sickle cell disease includes: fever and infection, neurologic, acute chest syndrome, priapism, splenic sequestration and sickle cell pain. ${ }^{1-5}$

A major complication of SCD is acute pain also known as vaso-occlusive crisis (VOC). Vaso-occlusive crisis is a common pain complication that can be debilitating. ${ }^{3,5}$ There is considerable variability in the way sickle cell disease pain is managed in the hospital, but subcutaneous, intramuscular, or intravenous opiates are commonly used to control severe pain. The variation in practice reflects different views about the suitability of opiates, the efficacy of parenteral and especially continuously infused or patient-controlled analgesia, and the risks of dependence on medication prescribed for the relief of sickle cell disease pain. ${ }^{6,7}$

Acute painful crisis is through to result when sickle hemoglobincontaining red blood cells become trapped in the microcirculation, leading sequentially to ischemia, infarction, reperfusion, inflammation, and tissue damage. ${ }^{5}$ Vaso-occlusive pain episode, also known as crisis, is often the most problematic feature of sickle cell disease. ${ }^{8}$ It is responsible for the majority of the emergency visits (79-91\%) and hospitalizations (59-68\%) with an average admission length of stay of 8 to 11 days. ${ }^{9}$ About $60 \%$ of patients with sickle cell disease have at least one episode of severe pain per year, with only a small group of patients accounting for more than $30 \%$ of hospital admissions for pain. ${ }^{10}$ In this case report, we discuss the perceptions of pain management from the point of view of three patients based on a verbal patient assessment.
Volume 4 Issue 4 - 2016

\author{
LaDonna M Oelschlaeger \\ Department of Pharmacy Practice, Marshall B Ketchum \\ University, USA
}

\begin{abstract}
Correspondence: LaDonna M Oelschlaeger PharmD, BCPS, Department of Pharmacy Practice, College of Pharmacy Marshall B. Ketchum University, Fullerton, USA, Tel (7I4) 87257/3, Email loelschlaeger@ketchum.edu
\end{abstract}

Received: April 14, 2016 | Published: May 24, 2016

Patient A is a 23year-old African American female with sickle cell disease and a history of cerebral and pulmonary embolism. She described her pain as similar to previous sickle cell crises, characterized as a gradual onset of strong, throbbing pain that is worse at night, during coughing, and deep breathing. Per the patient, she experiences a sickle cell crisis requiring hospitalization every two months. Her pain was not associated with any mitigating factors and ranged from 3 to 9 out of a 10 on a pain scale. She was given oral hydromorphone during outpatient treatment. When the medication failed to relieve her pain, she presented to the hospital for further pain treatment. Upon admission, the patient had a respiratory rate of 22 breaths per minute. Her body temperature, heart rate and blood pressure were all within normal limits. Oxygen saturation was $87 \%$ on room air. Laboratory test revealed a hemoglobin $7.3 \mathrm{~g} / \mathrm{dL}$, immature reticulocyte fraction $19.8 \%$, and platelets 549 billion/L. The patient received hydromorphone $2 \mathrm{mg}$ intravenously (IV) every three hours for pain, IV normal saline fluids, a blood transfusion, and oxygen. During hospitalization, she consistently complained of back and chest pains.

Patient B is a 26year-old African American female with a past medical history of sickle cell disease and MRSA infections. She presented to the hospital with severe upper and lower extremity and back pain. The patient's pain began one week prior to admission and was similar to that of previous sickle cell crises, of which the most recent episode requiring hospitalization was one month earlier. She described her pain as 10 out of 10 , worsening with movement. Prior to admission, the patient received fentanyl transdermal patch and oral morphine sulfate, both of which did not fully reverse the pain. As the patient's pain became more severe, she decided to go to the hospital for further treatment of pain. Upon admission, the patient had a respiratory rate of 110 beats per minute. Her temperature, heart rate and blood pressure were all within normal limits. The patient was breathing normal on room air. Laboratory tests showed hemoglobin of $8.0 \mathrm{~g} / \mathrm{dL}$ and reticulocyte of $16.1 \%$. For treatment, the patient was given IV fluids and hydromorphone $2 \mathrm{mg}$ IV every two hours as needed morphine sulfate $15 \mathrm{mg}$ to $30 \mathrm{mg}$ orally every six hours as needed for pain. 
Patient $\mathrm{C}$ is a 23year-old African American female with a history of cerebral stroke who presented to the clinic with bilateral hip and lower extremity pain. The patient's past medical history has been significant for sickle cell disease since the age of eleven months old. The patient stated that she has been frequently hospitalized for that sickle cell crisis since she can remember. Prior to this admission, the patient was hospitalized for sickle cell crises twice in the previous year. The patient had a baseline pain score of 4 to 5 out of 10 and in a crisis, her pain score ranged from 7 to 9 out of 10 . Her pain worsened two weeks ago and was similar to other sickle cell crises characterized as a gradual onset of aching. The patient described her pain as worse with cold weather and there were no relieving factors. Patient received oral morphine and amitriptyline, both of which failed to reverse her pain to baseline. A physical examination revealed normal vital signs and oxygen saturation on room air. Laboratory tests showed a WBC 13.43billion/L, $\mathrm{Hgb} 9.3 \mathrm{~g} / \mathrm{dL}$, and immature reticulocyte fraction $29.1 \%$. For pain management, the patient received hydromorphone $2 \mathrm{mg}$ IV every three hours as needed with the continuation of her home pain medications (morphine sulfate and amitriptyline) and IV fluids. The patient was discharged on the third day of admission. No blood transfusion was ordered for this patient because of a prior reaction to blood products.

Three individual patients were admitted to the same hospital for the management of the sickle cell crisis around the same time. Prior to discharge from the hospital, these patients were asked to assess their pain management by answering a few questions.

The most important questions asked were

I. If they were satisfied with the pain management and

II. What was one thing they would like to change about the hospital stay as it related to pain management?

\section{Results}

All three patients commented that they were satisfied with the pain regimens received during hospitalization. However, when asked to describe the experience in more detail, all shared some dissatisfaction. One stated that she waited too long for the pain medications and was discharged too early after only a couple of days of her hospital stay. Another patient stated that the nursing staff did not understand her condition and was too quick to judge on her use of the pain medications. The same patient also stated that she had been kicked out of another hospital prior to admission to the current one because of similar attitudes expressed with healthcare providers toward her request for pain medications. The third patient complained that the medical doctors criticized her for faking the pain as an attempt to receive more pain medications.

\section{Discussion}

Some patients have frequent vaso-occlusive pain episodes and require multiple hospital admissions, whereas other patients infrequently experience pain and rarely require hospitalization. ${ }^{11,12}$ Recurrent vaso-occlusive pain is the most common reason for hospitalization among patients with sickle cell disease; however, research indicates that the pain is often poorly managed in these types of patients. ${ }^{13}$ Our case represents three patients who were satisfied with the pain management received during hospitalization; however, their perceptions of how they were view by their healthcare providers in reference to requesting pain medications did not meet their expectations. It is difficult to assess pain accurately because assessment is influenced by one's socio-cultural factors. ${ }^{8}$ People often develop their attitudes and beliefs about pain and the use of opioids in pain management from within their families, churches, communities, ethnic background, and values. Therefore, patients' attitudes, beliefs, learned behaviors, and coping mechanisms may be entirely different from those of the healthcare providers. Recent literature suggests that patients are being better controlled with pain management; we believe this is a step in the right direction for patients and their perceptions about pain management. ${ }^{14,15}$

\section{Conclusion}

Patients with sickle cell disease suffering from vaso-occlusive pain episodes have various perceptions that may differ from their healthcare provider when it comes to pain management. There is a continuous need to address barriers associated with the perception of pain from the patient's point of view. The patient's experience is an important factor and can affect the overall outcome of care. In addition, implementing pain protocols to address patients' experiences and perceptions may be another way to help improve pain management in patients with sickle cell crisis.

\section{Acknowledgements}

None.

\section{Conflict of interest}

The author declares no conflict of interest.

\section{References}

1. Chan CY, Frei-Jones M. Sickle Cell Disease. Pharmacotherapy: A Pathophysiologic Approach. 9th ed. USA: McGraw Hill; 2014.

2. Center of Disease and Control (CDC). Sickle Cell Anemia.

3. Porter J, Feinglass J, Artz N, et al. Sickle Cell Disease Patients' Perceptions of Emergency Department Pain Management. J Natl Med Assoc. 2012;104(9-10):449-454.

4. NORD. Sickle Cell Disease. 2016

5. Telfer P, Bahal N, Lo A, et al. Management of the acute painful crisis in sickle cell disease-a re-evaluation of the use of opioids in adult patients. Br J Haematol. 2014;166(2):157-164.

6. McLafferty E, Farley A. Assessing pain in patients. Nursing Standard. 2008;22(25):42-46.

7. National Pain Survey conducted for Ortho-McNeil Pharmaceutical. 1999.

8. Wright K, Adeosun O. Barriers to effective pain management in sickle cell disease. Br J Nurs. 2009;18(3):158-161.

9. Yang Y, Sha A, Watson M, et al. Comparison of costs to the health sector of comprehensive and episodic health care for sickle cell disease patients. Public Health Rep. 1997;110(1):80-86.

10. Ellison AM, Shaw K. Management of vaso occlusive pain events in sickle cell disease. Pediatr Emerg Care. 2007;23(11):832-841.

11. Martin J, Moore G. Peals, pitfalls, and updates for pain management. Emergency Medicine Clinics of North America. 1997;15(2):399-415.

12. Tanabe P, Wafner JW, Martinovich Z, et al. Adult Emergency Department Patients with Sickle Cell Pain Crisis: Results from a Quality Improvement Learning Collaborative Model to Improve Analgesic Management. Acad Emerg Med. 2012;19(4):430-438.

13. Udezue E, Herrera E. Pain Management in Adult Acute Sickle Cell Pain Crisis: A View Point. West African Journal of Medicine. 2007;26(3):179-182. 
14. Ballas SK. Current Issues in Sickle Cell Pain and its Management Hematology Am Soc Hematol Educ Program. 2007;2007:97-105.
15. Steinberg M. Management of sickle cell disease. NEMJ. 1999;340(13):1021-1030. 